filiations between American and Canadian universities and institutions across Africa by demonstrating that, though Africa has long been neglected as a site of ground-breaking research; and knowledge production across the disciplines, the continent-its institutions, scholars, and students-can no longer be ignored if American and Canadian universities are in fact committed to producing globally rigorous scholarship and world-class students.

The program will focus on three-key areas: increased research collaboration; curriculum codevelopment between diaspora academics, their home institutions, and African institutions and faculty; and graduate student teaching and mentoring. Unlike existing exchange programs, in this program African institutions will drive the structure of exchanges and engage the desire of diaspora academics to contribute to higher education across Africa. Through the program, African institutions in Ghana, Kenya, Nigeria, South Africa, Tanzania, and Uganda submit a proposalrequesting the expertise of a diaspora scholar in the three areas or to be matched with an interested diaspora scholar for the appropriate disciplinary expertise.

The goal of this program and model to ensure that African institutions are the driving forces in identifying needs and opportunities for engagement, as well as providing to diaspora scholars and African institutions the space to build and expand their scholarly alliances. While the brain drain is a very real phenomenon, engaging the African academic diaspora and establishing programs to promote academic exchanges and collaborations holds potential for internationalizing and strengthening the capacities of African universities.

\section{China: Reforming the Gaokao}

\section{Gerard A. Postiglione}

Gerard A. Postiglione is Chair in Sociology and Education Policy, associate dean for research, and director of the Centre of Research on Education in China, Faculty of Education, University of Hong Kong, China.E-mail: postiglione@hku.hk.

nother reform is soon to be under way for China's Agaokao - the national college and university entrance exam that remains the greatest determinant of a Chinese student's life chances. Beside the reform of the English component (see Yang Rui in IHE No. 75: 12-13), there is a new move to align the test with China's moderating economic growth. In this sense, the gaokao is also a barom- eter of the challenges facing China's economic rise and its breakneck expansion of higher education.

\section{China's Dictum: Seek Truth From Facts}

Fact one: Before graduation last May 20I3, only about half of the nearly 7 million graduates had signed job contracts. Many university graduates would come to find themselves underemployed and facing a skills-mismatch problem. In a nation that is still more rural than urban and that families must make great sacrifices to pay for their children's higher education, it is disconcerting to the average parent when a student who passes the grueling national examination and attends university cannot find a good job.

Fact two: I7 million high school and college graduates enter the labor market every year, but state planners are concerned that the nation suffers from a shortage of talent, particularly in technical fields. Although China will have almost 200 million college graduates by 2020 , it will require far more expertise to elevate the value chain for equipment manufacturing, information technology, biotechnology, new materials, aeronautics and astronautics, oceanography, finance and accounting, international business, environmental protection, energy resources, agricultural technology, and modern traffic and transportation. To sustain its economic rise, the nation has to wean itself off of low-wage assembly export manufacturing. While it has top-notch scientists, it cannot upgrade its manufacturing sector without a greater number of well-trained technicians. While there is still concern that the education system does not encourage innovation and creativity, there is also a demand for technicians with a higher education that can support the ratcheting up of production.

Fact three: Students and their families still view technical-professional education as second class. The viewpoint dies hard, since academic higher education traditionally has equaled a stable job with government agency.

\section{Pending Reforms}

Thus, China will soon unveil a reform plan for the gaokao, which will divide it into two separate test modes, one for technically inclined students and the other for the more traditionally academically oriented students. The technical gaokao leads to higher technical and professional education-specifically toward admission to 600 technical and professional colleges and universities.

The first mode, targeting technically inclined students, is meant to appeal to those who want to become engineers, senior mechanics, and so-called high-quality laborers. It will assess students' technical skills, as well as textbook knowledge. The second mode still targets the standard academic student and examines characteristically academic knowledge. 
The 600 institutions of higher education that will be identified by the Ministry of Education would account for half of the total of public universities. They are being asked to restructure their teaching programs from academic education to applied technology and professional education.

\section{More Student Choice Can Equal Social Stability}

The government hopes this new gaokao reform will help propel the National Talent Development Plan and the National Plan for Medium- and Long-term Education Reform and Development. While this gaokao reform is sure to influence China's future higher education development, students will be the ones to make the choice. Their decision,

\section{Thus, China will soon unveil a reform plan for the gaokao, which will divide it into two separate test modes, one for technically inclined students and the other for the more traditionally academ- ically oriented students.}

to undertake gaokao mode one or two, means that their life chances will be set by about age $\mathrm{I} 6$, when they are still in high school. And in fact, there is some reason to believe that many more will consider signing on to model one gao$k a o$. Even before the reform some families wised up to the changing job market, in which graduates of professional/ technical colleges were finding jobs and college graduates were struggling to anchor themselves in the workplace.

This is a critical point for a country that prizes a harmonious society and watches with concern at the instability in neighboring Thailand, Myanmar, and Ukraine (not to mention the Taiwan student movement). A large population of unemployed university graduates can spell trouble and become destabilizing —often overnight and with little warning.

\section{Different Models}

After years of interest in the American community college model as a way to calibrate the rapid expansion of higher education, there is now a growing preference for something more akin to the German model of technical professional education. Only China's top-tier universities continue to look toward America's leading universities, for ideas about how to build world-class research universities. For the rest, it is looking elsewhere. China wants talented workers in engineering, mechanics, and related fields to gain an education that goes beyond mere skill training and demands more expertise, in short-skilled workers better equipped with academic knowledge.

For this reform to work as planned, there are several hurdles. First, transforming 600 local-level public universities into higher technical and vocational universities will significantly alter the differentiation and stratification of the public system of higher education. This is not a small reform, and its success hinges on external efficiency-alignment with the changing workplace among other things. In short, the reform has to provide jobs and boost a higher quality of manufacturing and industrial output.

Second, the reform has to break a deep-seated aversion to anything but academic learning in higher education. This is not easy anywhere, no less in China where the wellknown Confucian value placed on education-one that has changed the world - does not equate with vocational education. There is a reason for slight optimism. In 2013, according to the Ministry of Education, I.4 million high school graduates sought higher vocational education. In Shanghai, it was I5 percent of high school graduates in 2013.

An only concern about this reform is not just its ability to change the hierarchy in people's minds about the superiority of an academic education, but how to revalue the cultural capital of a nonacademic degree when it comes to employment and social status. If nonacademic degrees become the ambit of rural students, it may further institutionalize and stratify society, further intensifying the urban-rural divide. Impoverished rural areas constitute a continually shrinking proportion of students in top-tier universities. There is reason to expect that they will be encouraged to veer toward mode-one gaokao by educational officials and school teachers. To offset their underrepresentation in top-tier universities, the Ministry of Education has already decided to increase the quota for these students in 20I4from to central and western provinces, from 30,000 in 2013 to 50,000 . As top-tier universities gain more autonomy in student election, they are being asked to do the same.

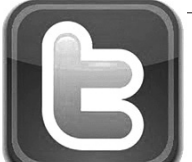

In addition to our Web site and Facebook page, we are now tweeting. We hope you will consider "following" us on Twitter! 